\title{
Tagging QTLs for late blight resistance and plant maturity from diploid wild relatives in a cultivated potato (Solanum tuberosum) background
}

\author{
J. Śliwka • H. Jakuczun • R. Lebecka $\cdot$ W. Marczewski • \\ C. Gebhardt $\cdot$ E. Zimnoch-Guzowska
}

Received: 1 June 2006 / Accepted: 10 April 2007 / Published online: 28 April 2007

(C) Springer-Verlag 2007

\begin{abstract}
Phytophthora infestans causes an economically important disease of potato called late blight. The epidemic is controlled chemically but resistant potatoes can become an environment-friendly and financially justified alternative solution. The use of diploid Solanum tuberosum derived from European tetraploid cultivars enabled the introgression of novel genes encoding foliage resistance and tuber resistance from other species into the modern cultivated potato gene pool. This study evaluated the resistance of the obtained hybrids, its quality, expression in leaflets and tubers and its relation to the length of vegetation period. We also identified genetic loci involved in late blight resistance and the length of vegetation period. A family of 156 individuals segregating for resistance to late blight was assessed by three laboratory methods: detached leaflet, tuber slice and whole tuber test, repeatedly over 5 years. Length of vegetation period was estimated by a field test over 2 years. The phenotypic distributions of all traits were close to normal. Using sequence-specific PCR markers of known chromosomal position on the potato genetic map, six quantitative trait loci (QTLs) for resistance
\end{abstract}

Communicated by C. Hackett.

Electronic supplementary material The online version of this article (doi:10.1007/s00122-007-0546-9) contains supplementary material, which is available to authorized users.

J. Śliwka $(\bowtie) \cdot$ H. Jakuczun · R. Lebecka ·

W. Marczewski · E. Zimnoch-Guzowska

Research Centre Młochów, Plant Breeding and Acclimatization Institute, Platanowa 19, 05-831 Mlochow, Poland

e-mail: j.sliwka@ihar.edu.pl

C. Gebhardt

Max Planck Institute for Plant Breeding Research, Carl-von-Linné Weg 10, 50829 Cologne, Germany and length of vegetation period were identified. The most significant and robust QTL were located on chromosomes III (explaining $17.3 \%$ of variance observed in whole tuber tests), IV (15.5\% of variance observed in slice tests), X (15.6\% of variance observed in leaflet tests) and V (19.9\% of variance observed in length of vegetation period). Genetic characterization of these novel resistance sources can be valuable for potato breeders and the knowledge that the most prominent QTLs for resistance and vegetation period length do not overlap in this material is promising with respect to breeding early potatoes resistant to $P$. infestans.

Keywords Introgression · Foliage resistance · Phytophthora infestans . Tuber resistance

\section{Introduction}

Late blight of potato and tomato is caused by the oomycete Phytophthora infestans (Mont.) de Bary. This economically very important disease attacks both foliage and tubers of potato and demands constant chemical protection of the crop, which is expensive as well as harmful for the environment. Potatoes resistant to late blight can be an alternative solution to chemical control. However, resistance of commercial value should be highly effective, durable and not linked with unwanted traits such as long vegetative period. So far, this has not been found within the gene pool of cultivated potato, where a linkage between the resistance and a long vegetation period is well documented (Świeżyński 1990). Most of the late blight resistance present within potato cultivars originates from Solanum demissum, and their lateness used to be attributed to the linkage drag (Umaerus and Umaerus 1994). Both R genes and QTLs for late blight resistance have been introduced from S. demissum, 
and although theoretically the $\mathrm{R}$ genes are considered as easier to separate from long vegetation period than QTL, there are still examples of linkage between the $\mathrm{R}$ genes and maturity type. The best-known example is the $R l$ gene, which is located within the QTL for vegetation period length on chromosome V. Moreover, it was shown in two independent studies (Gebhardt et al. 2004, Beketova et al. 2006) that cultivars possessing $R l$ show significantly longer vegetation period than the control group of cultivars. According to Świeżyński (1990), long vegetation period and horizontal resistance to late blight are manifestations of the same physiological phenomenon. This thesis is supported by Allefs et al. (2005) postulating that late blight resistance is always either "maturity related" or " $R$ gene based". It is still unclear whether the relationship between long vegetation period and late blight resistance results from genuine genetic linkage between functionally unrelated genes or from the pleiotropic effect of a gene influencing both traits (Visker et al. 2003, 2005). The most prominent quantitative trait locus (QTL) for plant maturity has been identified on potato chromosome V, which overlaps with QTL for late blight resistance (Collins et al. 1999; Oberhagemann et al. 1999; Bormann et al. 2004; Bradshaw et al. 2004; Visker et al. 2003, 2005).

Although $R$ gene-based resistance to $P$. infestans proved to be non-durable (Niederhauser et al. 1954; Malcolmson 1969, Rudkiewicz 1985), field resistance is believed to be more stable and therefore it seems to be more useful for breeders (Landeo et al. 1995). However, different breeding strategies are in use, among them the search for new, more durable $R$ genes (van der Vossen et al. 2005), building $R$ gene pyramids and combining $R$ gene-based and horizontal resistances, which is well supported by the hypotheses that those types of resistance are closely related or even inseparable.

Another issue in breeding potatoes resistant to late blight is tuber resistance that becomes even more important in organic farming where unprotected and blighted foliage is an inoculum source for the tubers. Only some genotypes of potato are resistant to $P$. infestans both in foliage and in tubers, some are resistant in foliage and susceptible in tubers and a few behave in the opposite way (Świeżyński and Zimnoch-Guzowska 2001). Most probably these resistance genes which are constitutively expressed provide the resistance of all plant organs simultaneously; however, some of the resistance genes are expressed either in specific tissue or plant development phase only. Stewart et al. (1994) tested several potato progenies and noted a strong correlation between tuber resistance to $P$. infestans and foliage resistance. Mapping of these two resistance components indicated the overlap of QTLs for foliage and tuber resistance with the most important QTL for plant maturity located on chromosome V (Collins et al. 1999; Oberhagemann et al.
1999; Bradshaw et al. 2004). The effect of $R$ genes in tubers has been investigated for the genes $R 1, R 2$ and $R 3$ from $S$. demissum showing the efficacy of $R I$ both in foliage and in tubers in contrast to $R 2$ and $R 3$, which have been efficient only in foliage (Roer and Toxopeus 1961). Recently, the functionality of $R 1$ both in foliage and in tubers, and foliage specificity of $R 3 a$ have been confirmed, and for another investigated $R$ gene Rpi-abpt foliage specificity has been shown (Park et al. 2005). A similar study was performed for Rpi-phul of S. phureja, which was shown to be highly effective both in foliage and in tubers (Śliwka et al. 2006). Tuber resistance assessment is very important while introducing a novel source of resistance to $P$. infestans into a breeding program because the relation of potato tuber and foliage resistance is a genotype-dependent trait.

In the present study two wild diploid species of potato, series Tuberosa, S. verrucosum Schlecht. and S. microdontum Bitt. were exploited as main sources of leaflet resistance to late blight, whereas sources of tuber resistance remained unidentified. The origin of resistance was defined on the basis of pedigree resistance analysis which is shown in ESM S1. Both species have long been described as resistant to P. infestans (Rudkiewicz 1985; Hawkes 1990). S. microdontum is believed to be a source of horizontal resistance, because it comes from regions where P. infestans immigrated only in twentieth century, which suggests a possible lack of $R$ gene evolution (Sandbrink et al. 2000). Inheritance of late blight resistance originating from $S$. microdontum has been investigated, as well as the chromosomal localization of the underlying QTLs and three major QTLs for foliage resistance have been identified on chromosomes IV, V and X (Sandbrink et al. 2000). A major QTL for late blight resistance, explaining more than $60 \%$ of phenotypic variance has been also identified in another study on $S$. microdontum (Bisognin et al. 2005). Late blight resistance of S. verrucosum has not been characterized that precisely so far, although it was used in diploid potato breeding (Świeżyński et al 1991). The goal of this study was to assess new resistance to $P$. infestans in terms of its expression in foliage and tubers, its effectiveness in five consecutive years, its relation to plant maturity and its inheritance including the identification of regions in the potato genome linked with the resistance. A number of studies mapping late blight resistance and maturity in potato are presently available and genome regions important for these traits as well as sequence-specific PCR markers covering these regions are defined and published. We aimed to apply such chosen markers to tag the important chromosome regions and to check if they also play a significant role in our material. This should enable us to answer the question if our material introduces new quality of resistance without producing a dense genetic linkage map. 


\section{Materials and methods}

Plant material

The diploid potato mapping population 98-21 $(2 n=2 x=24)$ was obtained by crossing the clones DG 83-1520 (P1) and DG 84-195 (P2). Both parental clones contributed to resistance of the progeny and both were complex interspecific hybrids. Detailed pedigrees are shown in ESM S1. Based on the pedigree, the maternal clone DG 83-1520 theoretically consisted of $37.6 \%$ S. tuberosum (several $\mathrm{dH} t b r$ ), $28.1 \%$ S. chacoense (GLKS 66.51/6/6; PK 133), 12.5\% S. verrucosum (PI 195170), 12.5\% S. microdontum (PI 265575), 6.2\% S. gourlayi (INTA. 7356) and $3.1 \%$ S. yungasense (GLKS 67.107/3R), whereas the paternal clone DG 84-195 theoretically consisted of $81.3 \% \mathrm{~S}$. tuberosum (several $\mathrm{dH} t b r$ ), $15.6 \%$ S. chacoense (GLKS 66.51/6/6; CPC 3785) and 3.1\% S. yungasense (GLKS 67.107/3R). The accessions of $S$. verrucosum and S. microdontum were used in IHAR's breeding programs as donors of resistance to $P$. infestans; thus we can assume that they are main sources of resistance, especially foliage resistance in mapping population 98-21. The accessions of S. chacoense, S. gourlayi and S. yungasense were used in these programs as sources of high starch content or resistance to potato viruses but not of late blight resistance. Tuber resistance was inherited from DG 84-195 and it might have originated from one of the wild species contributing to this clone but we cannot exclude that higher resistance of this clone in tuber tests resulted from favorable gene combination. Besides in the pedigree of DG 84-195, there are two cultivars of $S$. tuberosum possessing the $R l$ gene from S. demissum: Apta and Aquila (http://www.eucablight.org); however, this gene should not be effective against contemporary Polish $P$. infestans isolates.

The unselected population consisted of 156 individuals. Four tetraploid Polish cultivars were used as resistance standards: Irys (susceptible in foliage and in tubers), Sokół (susceptible in foliage and moderately resistant in tubers), Bzura (resistant in foliage and susceptible in tubers) and Meduza (resistant in leaflets and moderately resistant in tubers). Additionally, we used two diploid potato hybrids DG 94-15 with resistant foliage and DG 94-668 with resistant tubers (Śliwka et al. 2006).

\section{P. infestans isolate}

The isolate MP 324 from pathogen collection of the Plant Breeding and Acclimatization Institute was applied to all resistance tests. The isolate collected in 1997 in Poland was of A1 mating type, highly aggressive, metalaxyl resistant and of complex race (1.2.3.4.5.6.7.8.10.11). Its virulence was confirmed on 11 differentials, each possessing a single $R$ gene $(R 1-R 11)$ from $S$. demissum (Black's differential set obtained from Scottish Agricultural Science Agency, Edinburgh, UK), each time parallel to detached leaflet tests. Before each resistance test, the isolate was multiplied at least twice on susceptible potato tissue.

Late blight resistance assessment

Three laboratory methods of late blight resistance assessment were applied: detached leaflet test, tuber slice test and whole tuber test, performed according to Zarzycka (2001a, b). The parental clones and standard cultivars were tested together with the population. The assessment of resistance in population 98-21 was done in five consecutive years, 1999-2003. Three or five leaflets, slices or tubers per genotype were tested in two replications on one or two dates each year. A droplet of 50 sporangia/ $\mu 1$ suspension, prepared as described by Zarzycka (2001a), was used as an inoculum in leaflet and slice tests. Lateral leaflets were collected from the middle parts of plants and placed on plastic trays on the wet wood wool, upside down and trays were covered with glass. After $24 \mathrm{~h}$ inoculation, the leaflets were turned over. Double slices, each $10 \mathrm{~mm}$ thick, were cut out from the middle part of the tuber, inoculated between the two slices and placed in glass-covered plastic trays. In the whole tuber test, the rose ends of tubers were wounded with 16 pins distributed over an area of $12 \times 12 \mathrm{~mm}^{2}$ and ca $2 \mathrm{~mm}$ deep into the tuber flesh. Whole tubers were sprayed with inoculum. After 6 days (leaflets and slices) or 14 days (whole tubers) of incubation in conditions supportive for disease development (high relative humidity, $16^{\circ} \mathrm{C}$ and in case of leaflets-constant light of about 1,600 lx), the resistance was scored in a 1-9 scale, where 9 was the most resistant.

Length of vegetation period assessment

Vegetation period length of the population 98-21, the parental clones and standard cultivars, was evaluated in the field in 2003 and 2004. In 2003, clones were planted on 28th of April and harvested on 18th of September, while in 2004 planting was on 6th of May and harvesting was on 23rd of September. Plots of each genotype (seven plants of each genotype) were evaluated once a week for senescent plants, starting from the beginning of August (49 days to harvest in 2003 and 54 days to harvest in 2004). The vegetation period of the plants that died before harvest were evaluated directly in days from planting. The plants, which were still alive at the end of season, were assessed on a 1-5 scale, where 5 indicated a green, flowering plant, and 1 a completely dry plant. The scale was converted into days of vegetation period by adding 7 days for each grade above 1 , which simulated vegetation prolonged beyond the harvest date (Ratuszniak and Komorowska-Jędrys 1995). 
DNA isolation, PCR, polymorphism of amplicons

Genomic DNA was extracted from $1 \mathrm{~g}$ fresh, young leaves of greenhouse-grown plants with the DNeasy Plant Maxi kit (Qiagen, Hilden, Germany). All 56 sequence-specific DNA markers were amplified under conditions described by Rickert et al. (2003). Information on type of PCR-markers, primer sequences, annealing temperatures and restriction enzymes used for CAPS (cleaved amplified polymorphic sequences) markers are summarized in Table 1. The amplified DNA fragments were separated on agarose gels stained with ethidium bromide or by SSCP (single strand conformational polymorphism) analysis (Plomion et al. 1999; Slabaugh et al. 1997; Bormann et al. 2004). For SSCP, $4 \mu \mathrm{l}$ of restriction digest was mixed with $8 \mu \mathrm{l}$ of denaturing solution ( $97 \%$ deionized formamide, $0.01 \mathrm{M} \mathrm{NaOH}, 0.05 \%$ xylene cyanol, $0.05 \%$ bromophenol blue), denatured by heating to $94^{\circ} \mathrm{C}$ for $4 \mathrm{~min}$ and put immediately on ice. Samples were then separated on $0.25 \times$ mutation detection enhancement (MDE) gels (BMA Bio Whittaker Molecular Applications, Rockland, ME, USA) in $53.4 \mathrm{mM}$ Trisborate, 1.2 EDTA buffer, pH 8.0 and 5\% glycerol with addition of $0.06 \% \mathrm{~N}, \mathrm{~N}, \mathrm{~N}^{\prime}, \mathrm{N}^{\prime}$-tetramethylethylenediamine (TEMED) and $0.05 \%$ ammonium persulfate. Gels were run at $1.5 \mathrm{~W}$ for approximately $17 \mathrm{~h}$ at room temperature and silver stained (Bormann et al. 2004).

\section{Statistical and linkage analyses}

The results of the assessments of late blight resistance and vegetation period length were analyzed using analysis of variance, which enabled estimation of the influence of the genotype, date, year and their interactions, the date was nested within a year. Mean resistance was calculated from scores of 3-5 leaflets, slices or tubers per replication and that was used as a single data point in ANOVA shown in ESM S2. Fitness to the normal distribution of the phenotypic data was checked by the Kolmogorov-Smirnov test. Data sets deviating from normal distribution were transformed $\left(x^{2}, \sqrt{ } x, \arcsin x\right)$. The relationship between components of resistance and length of vegetation period was evaluated by linear Pearson's correlation coefficients based on means over all the years. Marker-trait linkages were estimated by the Student's $t$ test. Only those marker/trait linkages with $P<0.001$ for at least 1 year were considered significant.

Fitness of allele segregation to the expected 1:1 ratio was checked by the $\chi^{2}$ test. All statistical analyses were performed using computer programs SPSS 10.0 for Windows (SPSS Inc., Chicago, IL, USA), GENSTAT (International Ltd: Hemel Hempstead, UK) and STATISTICA for Windows (Stat Soft, Inc., Tulsa, OK, USA). Marker alleles were scored as present or absent and assembled into linkage groups using the software package MAPRF (E. Ritter, NEIKER, 01080, Vitoria, Spain). In the output of MAPRF, there is a LOD for every pairwise linkage. In our set of marker data, recombination frequencies up to $30 \%=0.3$ have LOD values $>3$ (the likelihood of linkage is 1,000 times larger than the $\mathrm{H}_{0}$ hypothesis of no linkage). In other words, linkages up to 0.3 can be accepted for being real. Linkages larger than 0.3 were taken as putative: $\mathrm{LOD}<3$. The principles, on which MAPRF is built, are described by Ritter et al. (1990).

\section{Results}

Late blight resistance and vegetation period length assessments

Parent DG 83-1520 (P1) was more resistant than the standard potato cultivars in leaflet tests (mean score 7.1), although it was susceptible in slice and whole tuber tests. The diploid clone DG 94-15 was the most resistant in leaflet tests (mean score 8.0). Parent DG 84-195 (P2) was more resistant than all standards in whole tuber tests (mean score 7.1), but in slice tests cv. Meduza (mean score 6.1), diploid clones DG 94-668 (mean score 7.5) and DG 94-15 (mean score 7.5) were better than P2 (mean score 5.3). P2 was susceptible in leaflet tests. Both parental clones were late maturing, with a mean length of vegetation period longer than 140 days.

Distributions of the 5-year mean (1999-2003) results of leaflet, slice and tuber tests (Fig. 1), as well as distributions of results from single years (not shown), did not deviate significantly from normality, with the exception of the leaflet test in 2000 and the slice test in 2002. These data were transformed to obtain normal distributions. In leaflet and slice tests, the mean grades in the population 98-21 ranged from 1.0-9.0, whereas in the whole tuber tests the range was narrowed to 2.2-9.0. The distribution of mean results of vegetation period length deviated significantly from normality (Fig. 2). Analysis of variance showed significant effects of genotype, date and year of testing and interactions between these factors. Genotype had the largest influence on resistance, explaining $37.0 \%$ of the variance in leaflet tests, $54.0 \%$ in slice tests and $25.2 \%$ in whole tuber tests. The effect of the year of testing was strongest in tuber tests $(20.3 \%$ of variance explained), slightly weaker in leaflet tests $(18.7 \%)$ and weakest in slice tests $(5.0 \%)$. Genotype $\times$ year interactions explained additional 16.8 , 24.2 and $19.2 \%$ of the variance in leaflet, whole tuber and slice tests, respectively. For details on ANOVA see ESM S2. The data sets of vegetation period length from 2003 and 2004 were significantly correlated $(P<0.001, r=0.562)$. Significant correlations were also found between mean leaflet and slice resistance $(P<0.001, r=0.480)$, slice and 


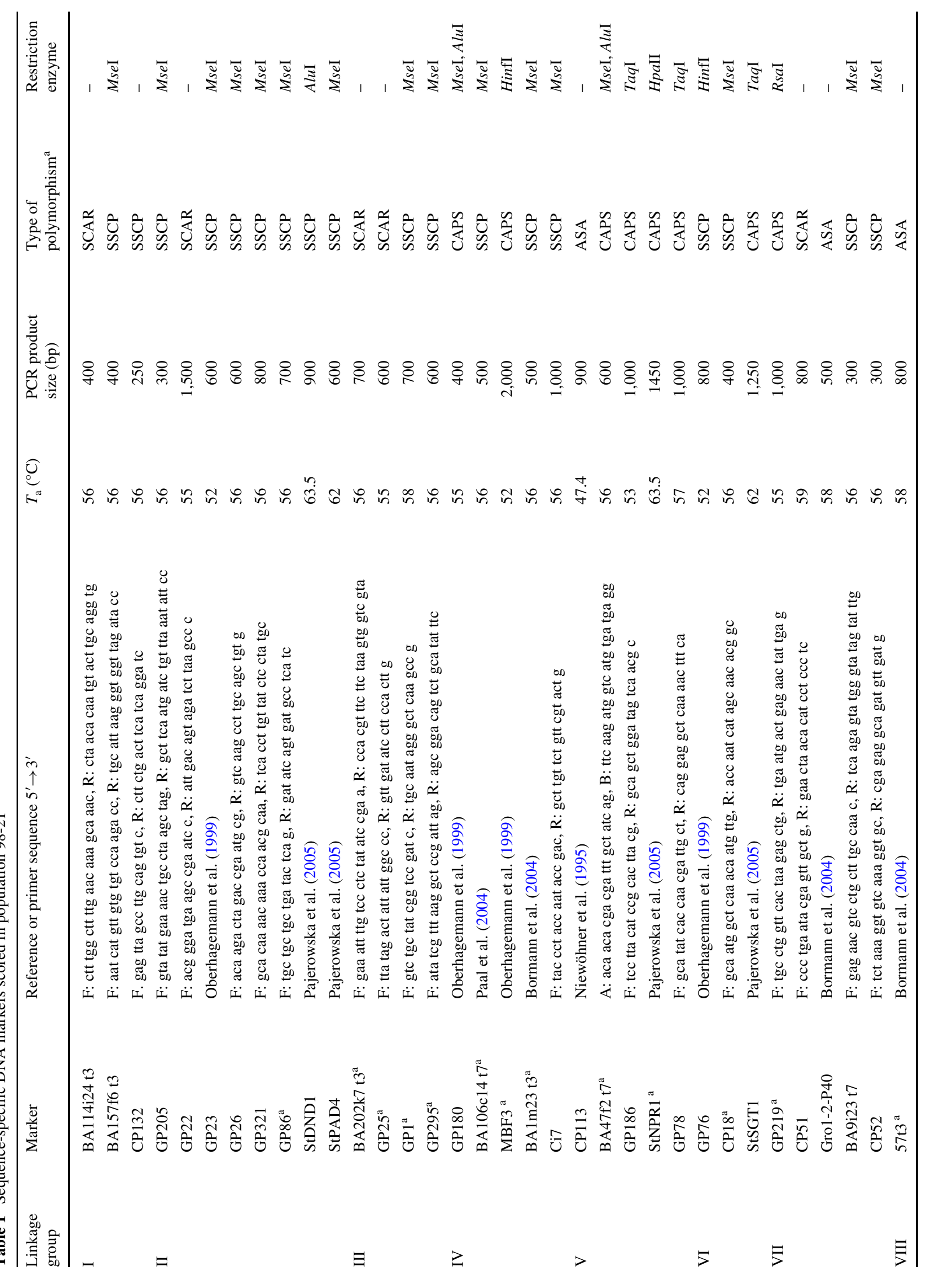




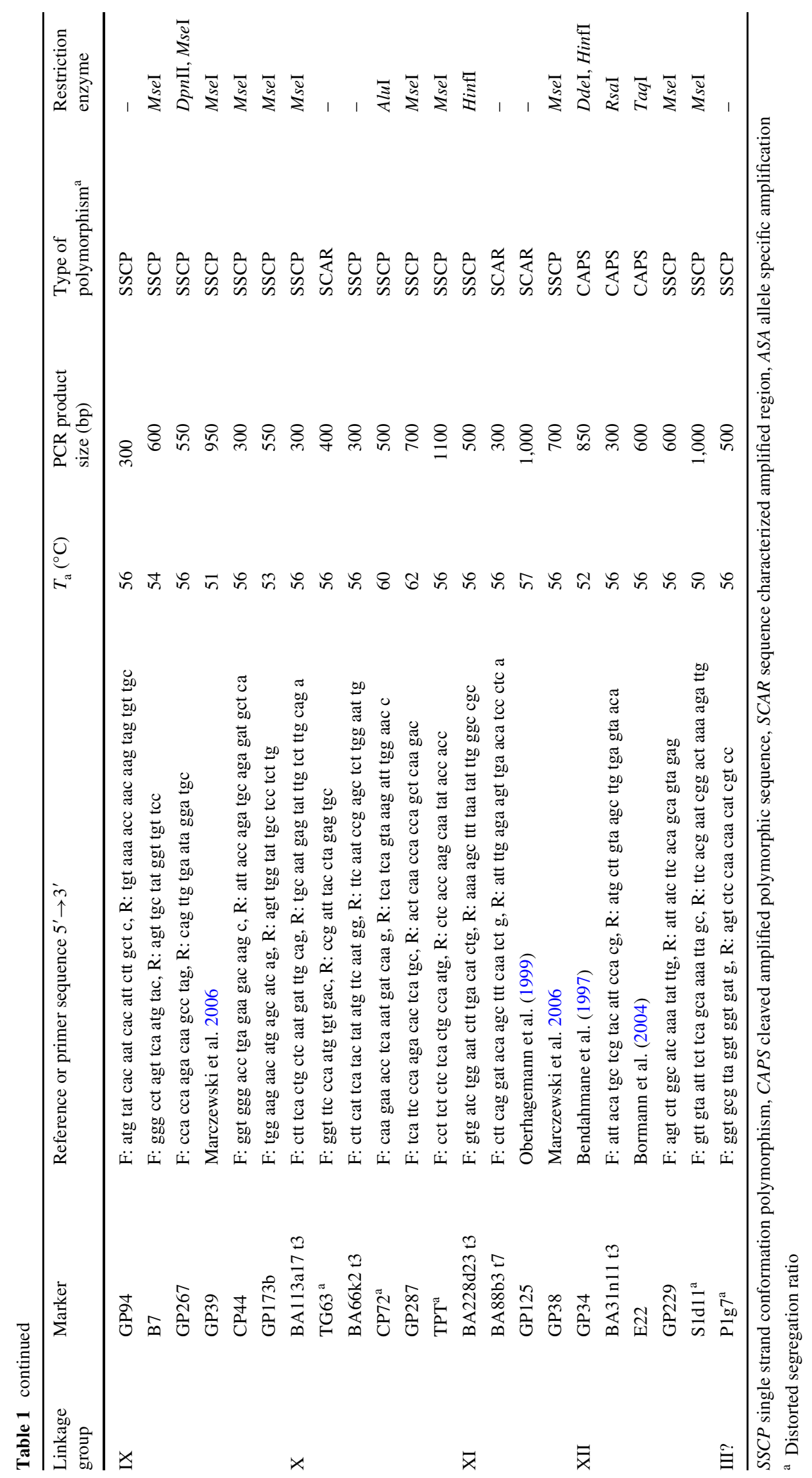



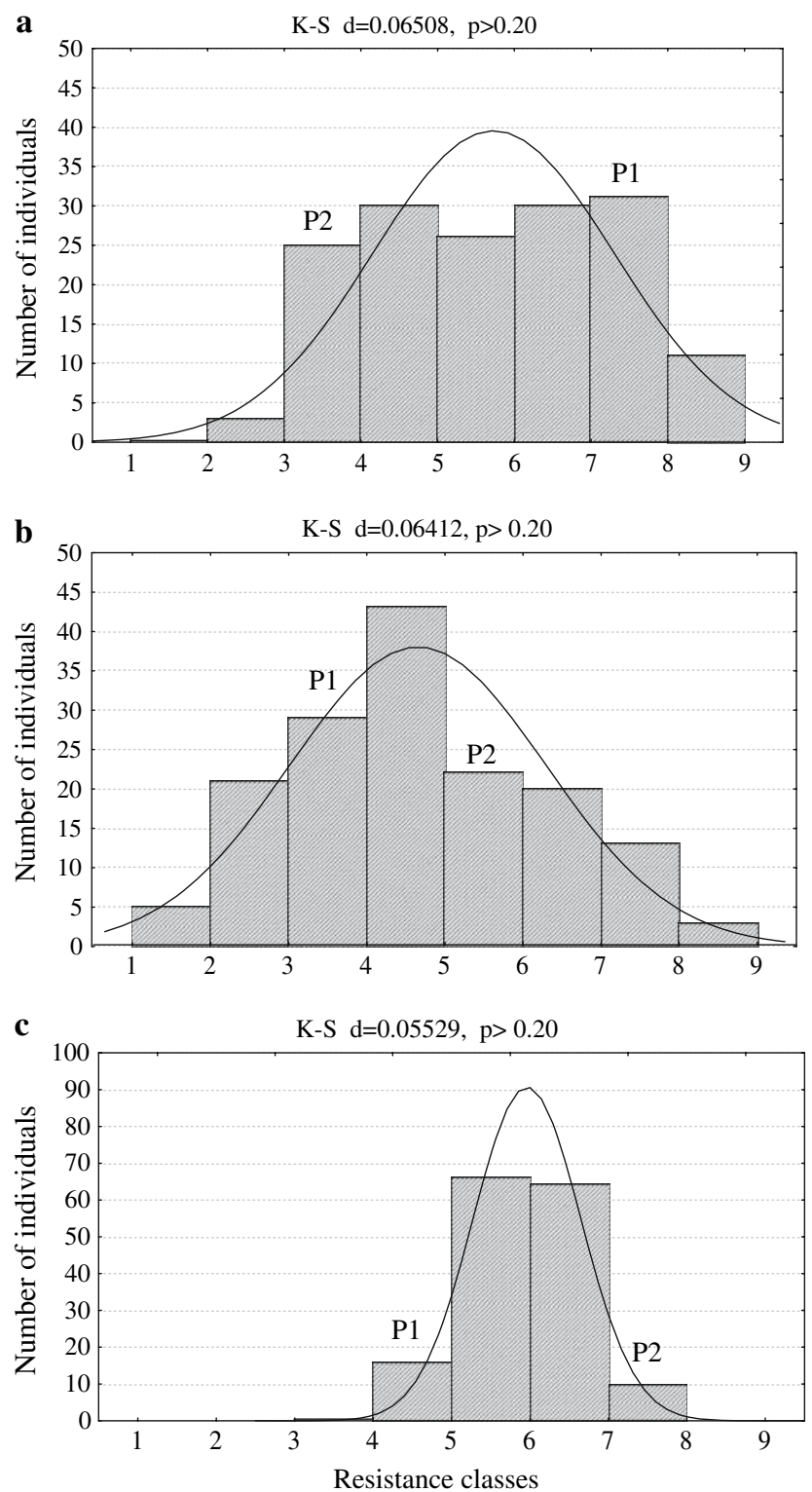

Fig. 1 Distributions of mean (1999-2003) leaflet (a), slice (b) and tuber $(\mathbf{c})$ resistance to $P$. infestans assessed in 1-9 scale, where 9 means the most resistant ( $x$-axis) in the population 98-21 and their fitness to the normal curve. $K$-S Kolmogorov-Smirnov test, $d$ coefficient calculated for this test, $p$ probability, the line indicates the normal curve. Resistance levels of parental clones is marked: P1 DG 83-1520, P2 DG 84-195

tuber resistance $(P<0.001, r=0.282)$ and between mean tuber resistance and mean length of vegetation period $(P<0.001, r=0.284)$. Correlations between the remaining trait combinations were not significant.

\section{Molecular linkage map}

Of the 56 DNA markers tested, 11 markers showed direct length polymorphism (SCAR or ASA), 12 were polymorphic after restriction digestion (CAPS), and SSCP analysis

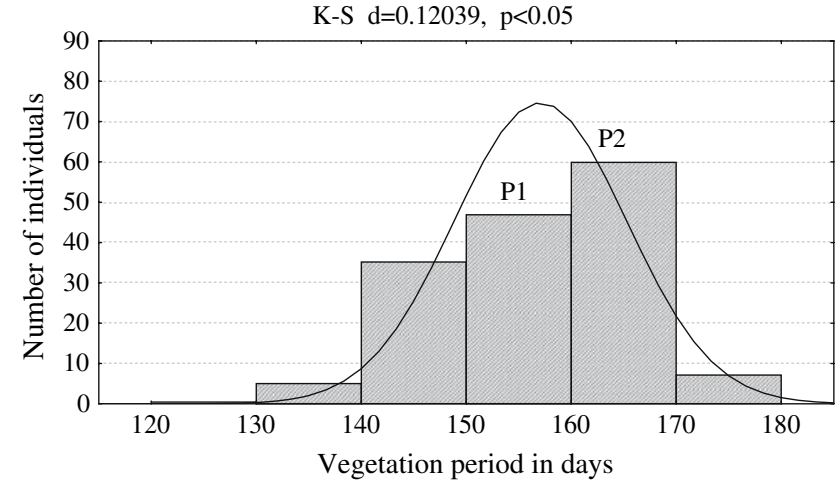

Fig. 2 Distribution of mean (2003-2004) vegetation period length (in days) in the population 98-21and its fitness to the normal curve. $K-S$ Kolmogorov-Smirnov test, $d$ coefficient calculated for this test, $p$ probability, the line indicates the normal curve. Vegetation period length of the parental clones is marked: P1 DG 83-1520, P2 DG 84-195

revealed 33 polymorphic marker alleles. Out of the 56 markers, 17 were co-dominant, which means 34 segregating alleles. The remaining 39 markers were inherited either from P1 or from P2, giving 73 segregating alleles in total. Among the 73 segregating marker alleles, 35 were inherited from P1 and 38 from P2. The marker alleles were scored in population 98-21 and assembled into separate linkage groups for P1 and P2. The chromosomes corresponding to the linkage groups were identified based on markers of known chromosomal position. Parental linkage groups corresponding to the same chromosome were joined by shared markers, with the exception of chromosome VII, where no shared marker allele was found. On chromosome VIII, only one marker allele was scored. The locations of the markers (Fig. 3) were mostly as expected from previous maps (http://gabi.rzpd.de/projects/Pomamo/; Rickert et al. 2003; Pajerowska et al. 2005), with the exception of ten markers (GP22, GP321, GP173, S1d11, BA157f6 t3, BA202k7 t3, BA1m23 t3, BA9i23 t7, BA31n11 t7, StNPR1), which mapped in population 98-21 to positions other than expected. This was most likely due to duplicated loci. Depending on whether the hybridization-based RFLP assay or PCR-based assays were used to score the marker, different copies of the markers were detected and mapped. Total map length for P1 was $509 \mathrm{cM}$ and for P2 was $447 \mathrm{cM}$, with the average distance between markers $12.7 \mathrm{cM}$. Segregation of 19 alleles was distorted from 1:1 ratio according to the $\chi^{2}$ test, ten out of them were grouped in three regions on chromosomes III, IV and X, whereas the remaining nine were located on chromosomes II, V, VI, VII and XII (Table 1).

\section{Quantitative trait loci}

In analysis of variance, the date of testing had little or no effect on the results. Marker-trait linkages were calculated 

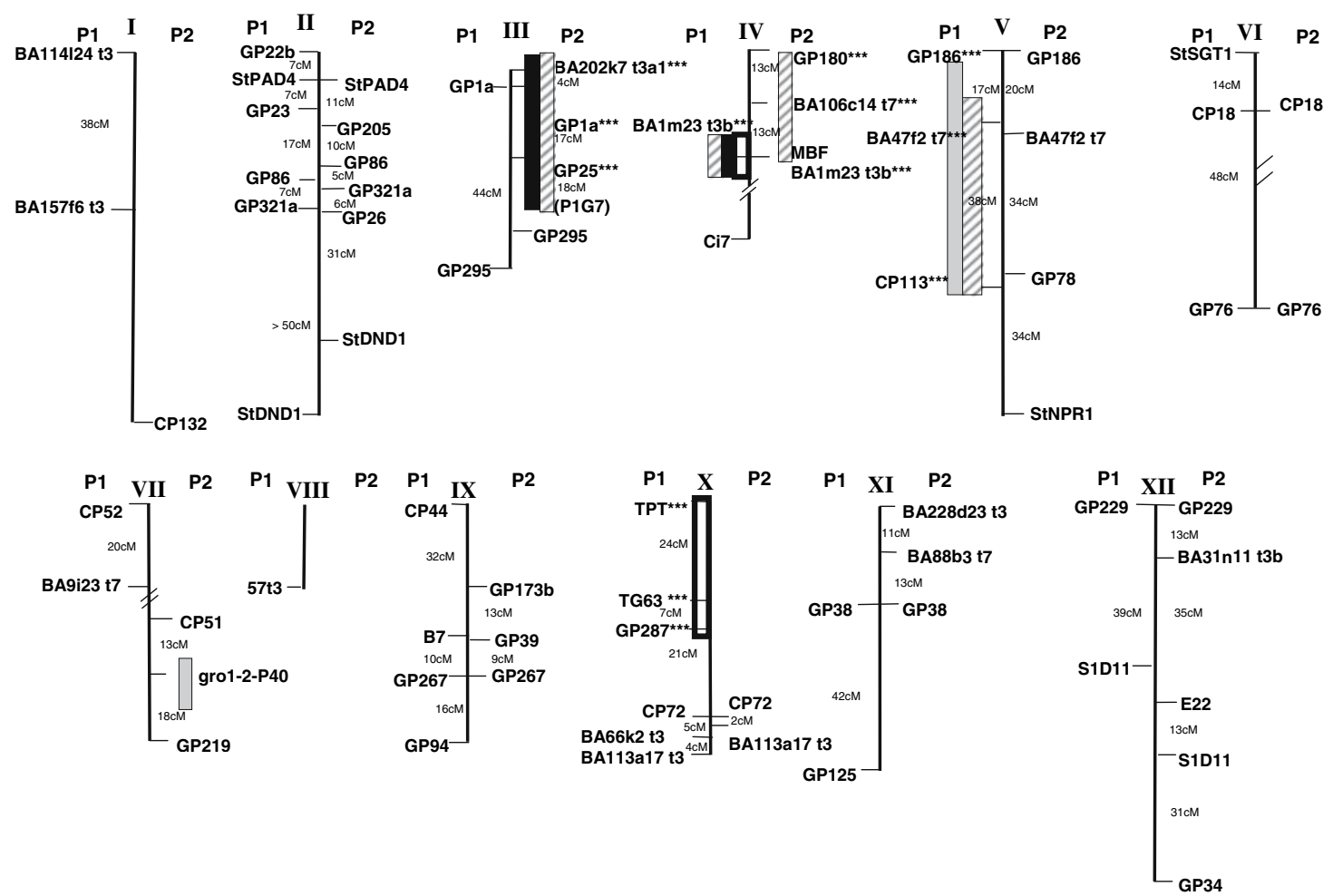

Fig. 3 Linkage and QTL map of the population 98-21 parents (P1DG 83-1520, P2-DG 84-195). QTLs for resistance to $P$. infestans in leaflets (white rectangles), slices (black), and tubers (stripes), and

therefore using the mean results of each year and the means over all test years (1999-2003 in case of late blight resistance and 2003-2004 for vegetation period length, Table 2). Fifteen marker alleles were significantly linked with the investigated traits forming 6 QTLs located on 5 chromosomes of potato (Fig. 3), when QTLs on chromosome IV were treated as two separate ones. Most of the QTLs influenced more than one trait. The association of marker alleles with increased or decreased resistance or length of vegetation period is indicated by arrows in Table 2. Significant marker-trait linkages were usually revealed only in some years of testing. The reason could be the use of leaflets and tubers from field grown plants which differed in their physiological state depending on the year and its weather and soil conditions. Possibly, various genetic factors and resistance mechanism were activated in consecutive years of testing depending on plants' state. The length of vegetation period was linked to marker alleles GP186 (P1) and BA47f2 t7 (P1) in both the years (Table 2). The most prominent QTL for leaflet resistance to $P$. infestans was inherited from P1 and was identified on chromosome X linked to markers TPT, GP287 and TG63. Marker allele TPT (P1) explained from $15.5 \%$ (2002) to $22.0 \%$ (2003) of the variance in detached leaflet tests depending on the year of testing and $15.6 \%$ of the variance on average,
QTLs for the vegetation period length (grey). Marker trait linkages, $t$ test probabilities: $* * * P<0.001$. Diagonal lines indicate putative linkages

although it did not show significant linkage to the resistance in 2000 and 2001. Resistance revealed by the tuber slice tests was influenced mostly by a QTL on chromosome IV, inherited from P1, which explained on average $15.5 \%$ of the variance in slice tests. Percentage of variance in slice resistance explained by this QTL varied from $9.0 \%$ in 2001 to $20.0 \%$ in 2000 , with no significant linkage in 2002 . QTL on chromosome IV had also some effects on leaflet resistance (in $200013.4 \%$ of variance explained) and whole tuber resistance (11.7\% in 2002) (Table 2). The strongest QTL for whole tuber resistance originating from P2 was found on chromosome III. It explained on average $17.3 \%$ of the variance. In 1999, 2001 and 2002 the effect of this QTL on tuber resistance was not significant. It explained 24.3 and $8.7 \%$ of variance in 2000 and 2003 , respectively. The QTL on chromosome III influenced also slice resistance (on average $8.1 \%$ of variance explained) but had no effect either on leaflet resistance to $P$. infestans or length of vegetation period (Table 2). Other QTL influencing whole tuber resistance was located on chromosome $\mathrm{V}$, linked to marker alleles BA47f2 t7 (P1) and CP113 (P1). Marker allele BA47f2 t7 (P1) explained on average $10.8 \%$ of variance in tuber resistance to late blight and $19.9 \%$ of variance in vegetation period length. This was the strongest QTL for vegetation period length and it was significant in both 2003 (24.7\% of 


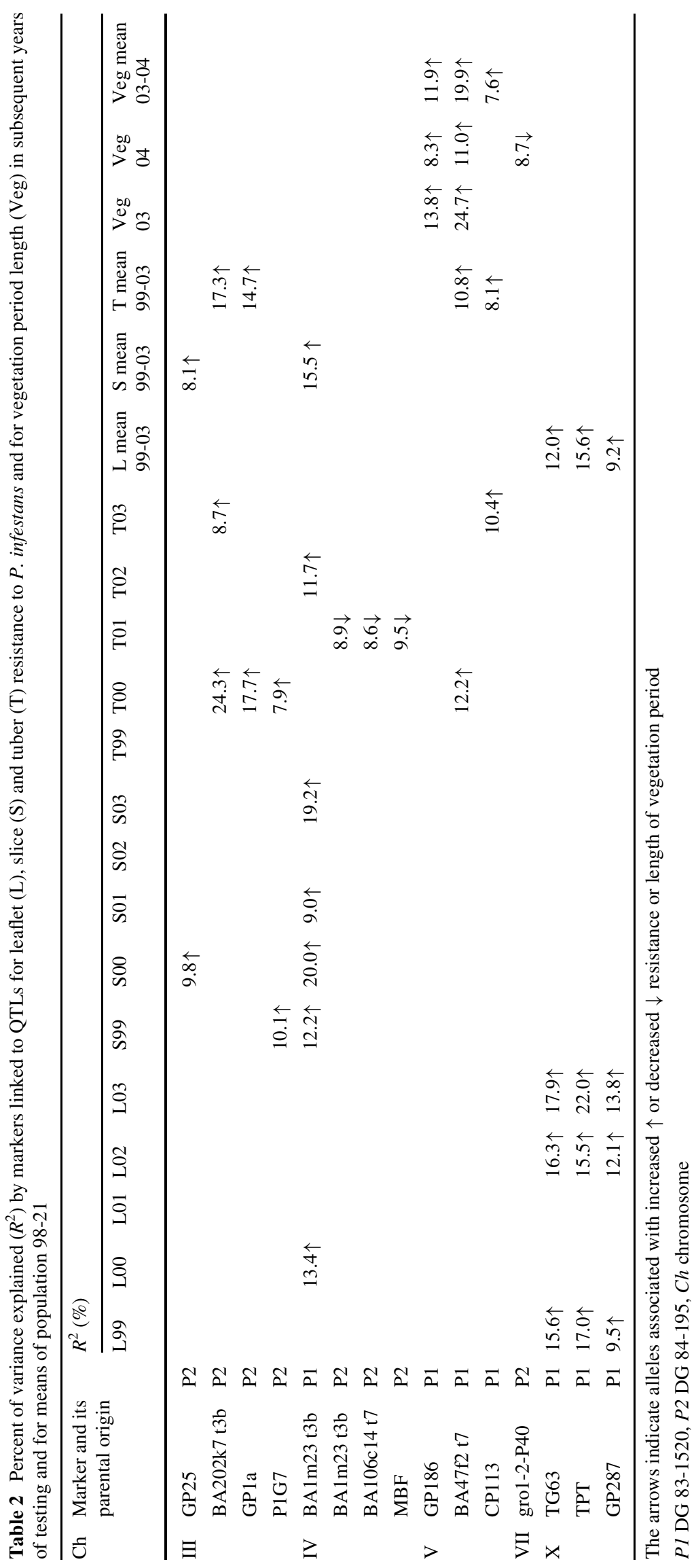


variance explained) and $2004(11.0 \%$ of variance explained) (Table 2). Later maturity was linked to higher resistance, because the same marker alleles were associated both with higher resistance and longer vegetation period (Table 2).

\section{Discussion}

In this study we characterized a novel source of resistance to late blight in diploid potatoes with complex pedigrees.

The expression of blight resistance depends on the inoculated tissue (Świeżyński and Zimnoch-Guzowska 2001). In other studies, where tuber blight resistance was mapped, whole undamaged tubers were inoculated, i.e. the periderm (Collins et al. 1999; Oberhagemann et al. 1999; Bradshaw et al. 2004). Park et al. (2005) compared two different slice tests and a test on whole wounded tubers and, because no differences were found, they chose the tuber test which was then used for evaluating the effects of some $R$ genes in tubers.

Leaflet resistance as well as slice and whole tuber resistance were analyzed in population 98-21. The tuber skin and the layer just below the tuber skin (inoculated in whole tuber tests) form two different, important barriers for the late blight infection (Toxopeus 1958, 1961). However, cortex and medulla (inoculated in slice tests) can also be involved in resistance mechanism (Flier et al. 2001). Three resistance components: leaflet, slice and whole tuber resistance showed normal distribution in population 98-21 (Fig. 1) and strong influence of the environment on those traits and therefore their quantitative character. Genetic analysis of slice resistance to $P$. infestans was done for the first time in our study. The markers used for QTL tagging were selected based on the assumption that most of the QTLs for the evaluated traits were already located on the potato genetic map in different mapping populations (Gebhardt 2004). The growing number of potato PCR markers with known chromosomal position recently published (Bormann et al. 2004; Rickert et al. 2003) and available in databases (http://www.gabi.rzpd.de and http://www. ncbi.nih.gov) allowed us to choose DNA markers from most targeted regions of the potato genome. Ten markers mapped in population 98-21 to positions other than expected. Markers GP22, GP173 and S1d11 were originally mapped in different mapping populations as RFLP bands, but in the present study they were applied as sequence-specific PCR markers. Taking into account that potato is a highly polymorphic heterozygous species and that the sequence duplications are common, we assumed that PCR primers, although designed on the basis of sequence of the RFLP bands, were more compatible with different loci in our genotypes. GP321 was mapped originally as an RFLP secondary band, whereas the main band, located differently, was not polymorphic (C. Gebhardt, personal communication). Most probably, in our study the PCR amplified this main band and polymorphism was detected within the fragment. Markers with names starting with BA...were BAC ends, of BAC clones hybridizing to RGL probes and mapped as RFLP (Rickert et al. 2003). The BAC ends were random and, quite likely, multi-copy sequences, which could have been the reason for their different mapping positions in our study, when compared to the original one (Rickert et al. 2003). An example of sequence similarity affecting PCR detection of particular locus in potato is described by Marczewski et al. (2006), where the PCR fragment linked to the $G m$ gene located on chromosome IX showed 94 and 84\% identity to sequences from chromosome XII and $87 \%$ identity to sequence from chromosome VIII. In such case differently located primers can quite likely amplify different loci.

The applied approach enabled tagging 6 QTLs. We used the expression 'QTL'; however, our study did not allow defining what genes are underlying the resistance in population 98-21. They may be polygenes as well as $\mathrm{R}$ genes. In fact, some researchers speculate that major genes are just very effective alleles at QTLs and that the borders between the two traditionally distinguished types of resistance can be blurred (Gebhardt and Valkonen 2001). Also, R genes overcome by pathogen can still have some residual effect, enhancing the quantitative resistance of the plant (Stewart and Bradshaw 2001; Stewart et al. 2003). QTLs for the resistance components and length of vegetation period in our study only partially overlapped (Fig. 3), which was a result corresponding well with low-correlation coefficient between the results of phenotypic assessments.

In previous studies (Leonards-Schippers et al. 1994; Collins et al. 1999; Oberhagemann et al. 1999; Sandbrink et al. 2000; Ghislain et al. 2001; Visker et al. 2003, 2005; Bormann et al. 2004; Bradshaw et al. 2004; Costanzo et al. 2005) the most frequently detected QTL for foliage and whole tuber resistance is located on chromosome $\mathrm{V}$, in the neighborhood of the $R I$ gene. In population $98-21$, this region harboured the strongest QTL for length of vegetation period, which also influenced leaflet and whole tuber resistance to late blight. The strongest and most robust QTLs for leaflet, slice and whole tuber resistance found in population 98-21 were located on chromosomes X, IV and III, respectively. The QTL for leaflet resistance on chromosome $\mathrm{X}$ is in a similar region as described by Sandbrink et al. (2000) as harbouring QTL for late blight resistance originated from $S$. microdontum. The QTL for tuber resistance on chromosome III corresponds with QTLs for foliage resistance to late blight detected in other genetic materials (Leonards-Schippers et al. 1994; Collins et al. 1999; Oberhagemann et al. 1999; Costanzo et al. 2005). 
The QTL for slice resistance found on chromosome IV influenced also leaflet and whole tuber resistance and most probably it corresponds to a QTL from $S$. microdontum described by Sandbrink et al. (2000). Leonards-Schippers et al. (1994), Oberhagemann et al. (1999) and Collins et al. (1999) detected QTLs for foliage resistance to late blight and plant maturity in similar locations. Bormann et al. (2004) described QTLs for plant maturity and for maturitycorrected resistance in this region, whereas Bradshaw et al. (2004) detected on chromosome IV a QTL for foliage resistance to $P$. infestans with no effect on maturity.

In population 98-21, the most significant and robust QTLs for resistance to $P$. infestans did not overlap with the strongest QTL for the length of vegetation period, which was a promising result with regard to selection of resistant and early potatoes originating from this source of resistance. Taking into account that our material was generally late we cannot be conclusive, but we can hypothesize that crossing it with early genotypes and selecting, possibly with markers, plants with certain genotypes at QTLs on chromosomes III, IV and X combined with negative selection for the QTL on chromosome V, could result in obtaining early potatoes resistant to late blight in next generations. Still, probably not all genetic factors involved in resistance to late blight and maturity of population 98-21 have been revealed in the present study due to the limited genome coverage. Analysis of marker-trait linkages with lowered stringency of significance, which detected 15 QTLs on all 12 chromosomes, can be an indication for that. The material was generally late maturing which could also influence mapping QTLs for maturity. Weak correlations between different resistance components noted for this source should be taken into consideration, when breeding potatoes resistant both in foliage and in tubers.

Acknowledgments The authors thank Agim Ballvora, Christina Bormann, Evgeniya Ilarionova, Karolina Pajerowska and Andreas Rickert (Max-Planck Institute for Plant Breeding Research, Cologne, Germany) for providing PCR primers as well as Zygmunt Kaczmarek and Marcin Przystalski (Institute of Plant Genetics, Polish Academy of Sciences, Poznań, Poland) for performing the analysis of variance.

\section{References}

Allefs JJHM, Muskens MWM, van der Vossen EAG (2005) Breeding for foliage blight resistance in the genomics era. In: Haverkort AJ, Striuk PC (eds) Potato in progress. Science meets practice. Academic, Wageningen, pp 255-267

Bendahmane A, Kanyuka K, Baulcombe DC (1997) High-resolution genetical and physical mapping of the $R x$ gene for extreme resistance to potato virus $\mathrm{X}$ in tetraploid potato. Theor Appl Genet 95:153-162

Beketova MP, Drobyazina PE, Khavkin EE (2006) The Rl gene for late blight resistance in early and late maturing potato cultivars. Russ J Plant Physiol 53:384-389
Bisognin DA, Douches DS, Buszka L, Bryan G, Wang D (2005) Mapping late blight resistance in Solanum microdontum Bitter. Crop Sci 45:340-345

Bormann CA, Rickert AM, Castillo Ruiz RA, Paal J, Lübeck J, Strahwald J, Buhr K, Gebhardt C (2004) Tagging quantitative trait loci for maturity-corrected late blight resistance in tetraploid potato with PCR-based candidate gene markers. Mol Plant Microbe Interact 17:1126-1138

Bradshaw JE, Pande B, Bryan GJ, Hackett CA, McLean K, Stewart HE, Waugh R (2004) Interval mapping of quantitative trait loci for resistance to late blight [Phytophthora infestans (Mont.) de Bary], height and maturity in a tetraploid population of potato (Solanum tuberosum subsp. tuberosum). Genetics 168:983995

Collins A, Milbourne D, Ramsay L, Meyer R, Chatot-Balandras C, Oberhagemann P, De Jong W, Gebhardt C, Bonnel E, Waugh R (1999) QTL for field resistance to late blight in potato are strongly correlated with maturity and vigour. Mol Breed 5:387-398

Costanzo S, Šimko I, Christ BJ, Haynes KG (2005) QTL analysis of late blight resistance in a diploid potato family of Solanum phureja $\times$ S. stenotomum. Theor Appl Genet 111:609-617

Flier WG, Turkensteen LJ, van den Bosch GMB, Verijken PFG, Mulder A (2001) Differential interaction of potato cultivars with different levels of blight resistance. Plant Pathol 50:292-301

Gebhardt C (2004) Potato genetics: maps and more. In: Lörtz H, Wenzel G (eds) Molecular marker systems in plant breeding and crop improvement. Biotechnology in agriculture and forestry. Springer, Heidelberg, pp 215-227

Gebhardt C, Valkonen JPT (2001) Organization of genes controlling disease resistance in the potato genome. Annu Rev Phytopathol 39:79-102

Gebhardt C, Ballvora A, Walkemeier B, Oberhagemann P, Schüler K (2004) Assessing genetic potential in germplasm collections of crop plants by marker-trait association: a case study for potatoes with variation of resistance to late blight and maturity type. Mol Breed 13:93-102

Ghislain M, Trognitz B, Herrera M del R, Solis J, Casallo G, Vásquez C, Hurtado O, Castillo R, Portal R, Orillo M (2001) Genetic loci associated with field resistance to late blight in offspring of Solanum phureja and S. tuberosum grown under short-day conditions. Theor Appl Genet 103:433-442

Hawkes JG (1990) The potato, evolution, biodiversity and genetic resources. Belhaven Press, London

Landeo JA, Gastelo M, Pinedo H, Flores F (1995) Breeding to horizontal resistance to late blight in potato free of $\mathrm{R}$ genes. In: Dowley LJ, Bannon E, Cooke LR, Keane T, O’Sullivan E (eds) Phytophthora infestans. Boole Press, Dublin, vol 150, pp 268-274

Leonards-Schippers C, Gieffers W, Schäfer-Pregl R, Ritter E, Knapp S J, Salamini F, Gebhardt C (1994) Quantitative resistance to Phytophthora infestans in potato: a case study for QTL mapping in an allogamous plant species. Genetics 137:67-77

Malcolmson JF (1969) Races of Phytophthora infestans occurring in Great Britain. Trans Br Mycol Soc 53:417-423

Marczewski W, Strzelczyk-Żyta D, Hennig J, Witek K, Gebhardt C (2006) Potato chromosomes IX and XI carry genes for resistance to potato virus M. Theor Appl Genet 112:1232-1238

Niederhauser JS, Cervantes J, Servin L (1954) Late blight in Mexico and its implications. Phytopathology 44:406-408

Niewöhner J, Salamini F, Gebhardt C (1995) Development of PCR assays diagnostic for RFLP marker alleles closely linked to alleles Gro1 and H1, conferring resistance to the root cyst nematode Globodera rostochiensis in potato. Mol Breed 1:65-78

Oberhagemann P, Chatot-Balandras C, Schäfer-Pregl R, Wegener D, Palomino C, Salamini F, Bonnel E, Gebhardt C (1999) A genetic analysis of quantitative resistance to late blight in potato: towards marker-assisted selection. Mol Breed 5:399-415 
Paal J, Henselewski H, Muth J, Meksem K, Menéndez CM, Salamini F, Ballvora A, Gebhardt C (2004) Molecular cloning of the potato Grol-4 gene conferring resistance to pathotype Rol of the root cyst nematode Globodera rostochiensis, based on a candidate gene approach. Plant J 38:285-297

Pajerowska KM, Parker JE, Gebhardt C (2005) Potato homologues of Arabidopsis thaliana genes functional in defense signalingidentification, genetic mapping and molecular cloning. Mol Plant Microbe Interact 18:1107-1119

Park T-H, Vleeshouwers VGAA, Kim J-B, Hutten RCB, Visser RGF (2005) Dissection of foliage and tuber blight resistance in mapping populations of potato. Euphytica 143:75-83

Plomion C, Hurme P, Frigerio J-M, Ridolfi M, Pot D, Pionneau C, Avila C, Gallardo F, David H, Neutelings G, Campbell M, Canovas FM, Savolainen O, Bodénès C, Kremer A (1999) Developing SSCP markers in two Pinus species. Mol Breed 5:21-31

Ratuszniak E, Komorowska-Jędrys J (1995) Metodyka prowadzenia badań I obserwacji w doświadczeniach wstępnych $\mathrm{z}$ rodami hodowlanymi (odmianami) ziemniaka (instrukcja). Instytut Ziemniaka, Bonin, Poland

Rickert AM, Kim JH, Meyer S, Nagel A, Ballvora A, Oefner PJ, Gebhardt C (2003) First-generation SNP/InDel markers tagging loci for pathogen resistance in the potato genome. Plant Biotechnol J 1:399-410

Ritter E, Gebhardt C, Salamini F (1990) Estimation of recombination frequencies and construction of RFLP linkage maps in plants from crosses between heterozygous parents. Genetics 125:645-654

Roer L, Toxopeus HJ (1961) The effect of R-genes for hypersensitivity in potato-leaves on tuber resistance to Phytophthora infestans. Euphytica 10:35-42

Rudkiewicz F (1985) Zaraza ziemniaka (Phytophthora infestans (Mont) de Bary). In: Gabriel W (ed) Biologia ziemniaka. Państwowe Wydawnictwa Naukowe, Warszawa, pp 381-398

Sandbrink JM, Colon LT, Wolters PJCC, Stiekema W (2000) Two related genotypes of Solanum microdontum carry different segregating alleles for field resistance to Phytophthora infestans. Mol Breed 6:215-225

Slabaugh MB, Huestis GM, Leonard J, Holloway JL, Rosato C, Hongtrakul V, Martini N, Toepfer R, Voetz M, Schell J, Knapp SJ (1997) Sequence-based genetic markers for genes and gene families: single-strand conformational polymorphisms for the fatty acid synthesis genes of Cuphea. Theor Appl Genet 94:400-408

Śliwka J, Jakuczun H, Lebecka R, Marczewski W, Gebhardt, Zimnoch-Guzowska E (2006) A novel late blight resistance gene Rpi-phul mapped to potato chromosome IX is not related to long vegetation period. Theor Appl Genet 113:685-695

Stewart HE, Bradshaw JE (2001) Assessment of the field resistance of potato genotypes with major gene resistance to late blight
(Phytophthora infestans (Mont.) de Bary) using inoculum comprised of two complementary races of the fungus. Potato Res 44:41-51

Stewart HE, Bradshaw JE, Wastie RL (1994) Correlation between resistance to late blight in foliage and tubers in potato clones from parents of contrasting resistance. Potato Res 37:429-434

Stewart HE, Bradshaw JE, Pande B (2003) The effect of the presence of R-genes for resistance to late blight (Phytophthora infestans) of potato (Solanum tuberosum) on the underlying level of field resistance. Plant Pathol 52:193-198

Świeżyński KM (1990) Resistance to Phytophthora infestans in potato cultivars and its relation to maturity. Genet Pol 31:99-106

Świeżyński KM, Zimnoch-Guzowska E (2001) Breeding potato cultivars with tubers resistant to Phytophthora infestans. Potato Res 44:97-117

Świeżyński KM, Sieczka MT, Sujkowski LS, Zarzycka H, ZimnochGuzowska E (1991) Resistance to Phytophthora infestans in potato genotypes originating from wild species. Plant Breed 107:28-38

Toxopeus HJ (1958) Some notes of the relations between field resistance to Phytophthora infestans in leaves and tubers and ripening time in Solanum tuberosum subsp. tuberosum. Euphytica 7:123-130

Toxopeus HJ (1961) On the inheritance of tuber resistance of Solanum tuberosum to Phytophthora infestans in the field. Euphytica 10:307-314

Umaerus V, Umaerus M (1994) Inheritance of resistance to late blight. In: Bradshaw JE, Mackay GR (eds) Potato genetics. CAB International, Wallingford, pp 319-337

Van der Vossen EAG, Gros J E, Sikkema A, Muskens M, Wouters D, Wolters P, Pereira A, Allefs S (2005) The Rpi-blb2 gene from Solanum bulbocastanum is an Mi- 1 gene homolog conferring broad-spectrum late blight resistance in potato. Plant J 44:208222

Visker MHPW, Keizer LCP, van Eck HJ, Jacobsen E, Colon LT, Struik PC (2003) Can the QTL for late blight resistance on potato chromosome 5 be attributed to foliage maturity type? Theor Appl Genet 106:317-325

Visker MHPW, Heilersig HJB, Kodde LP, Van de Weg WE, Voorrips RE, Struik PC, Colon LT (2005) Genetic linkage of QTLs for late blight resistance and foliage maturity type in six related potato progenies. Euphytica 143:189-199

Zarzycka H (2001a) Evaluation of resistance to Phytophthora infestans in detached leaflet assay. Preparation of the inoculum. Monografie i Rozprawy Naukowe IHAR, Radzików, Poland, vol 10a, pp 75-77

Zarzycka H (2001b) Assessment of resistance to Phytophthora infestans in tuber slices and whole tubers. Monografie i Rozprawy Naukowe IHAR, Radzików, Poland, vol 10a, pp 78-80 